\title{
Regulation of mucosal immune responses in effector sites
}

\author{
M. Bailey ${ }^{1 *}$, F. J. Plunkett ${ }^{1}$, H.-J. Rothkötter ${ }^{2}$, M. A. Vega-Lopez ${ }^{3}$, K. Haverson ${ }^{1}$ and C. R. Stokes ${ }^{1}$ \\ ${ }^{1}$ Division of Molecular and Cellular Biology, Department of Clinical Veterinary Sciences, University of Bristol, Langford \\ House, Langford, Bristol BS40 5DU, UK \\ ${ }^{2}$ Department of Functional Anatomy, Hannover Medical School, 4120 Carl-Neuberg Str., 30625 Hannover, Germany \\ ${ }^{3}$ CINVESTAV-IPN, Experimental Pathology Department, Av. IPN 2508, Mexico 07360 DF, Mexico
}

\begin{abstract}
In human disease and rodent models, immune responses in the intestinal mucosa can be damaging. Damage is characterised by villus atrophy, crypt hyperplasia and reduced ability to digest and absorb nutrients. In normal individuals active responses to harmless environmental antigens associated with food and commensal bacteria are controlled by the development of immunological tolerance. Similar pathological changes occur in piglets weaned early from their mothers. Active immune responses to food antigens are observed in these piglets, and we and others have hypothesised that the changes occur as a result of transient allergic immune responses to novel food or bacteria antigens. The normal mechanism for producing tolerance to food antigens may operate at induction (Peyer's patches and mesenteric lymph nodes) or at the effector stage (intestinal lamina propria). In our piglet studies immunological tolerance occurs despite the initial active response. Together with evidence from rodents, this observation suggests that active responses are likely to be controlled at the effector stage, within the intestinal lamina propria. Support for this mechanism comes from the observation that human and pig intestinal T-cells are susceptible to apoptosis, and that this process is accelerated by antigen. We suggest that the role of the normal mature intestinal lamina propria is a balance between immunological effector and regulatory function. In neonatal animals this balance develops slowly and is dependant on contact with antigen. Immunological insults such as weaning may tip the balance of the developing mucosal immune system into excessive effector or regulatory function resulting in transient or chronic allergy or disease susceptibility.
\end{abstract}

Weaning: Immunity: Tolerance: Development

\section{Expression of mucosal tolerance at the effector stage}

The need for the mucosal immune system to control local immune responses to harmless antigens is apparent from the severe pathology which can be induced in individuals allergic to food antigens. Experimentally, expression of this control is demonstrated by the classical 'oral tolerance' protocol, in which feeding a novel protein antigen to a group of animals results in a decreased immune response when they are subsequently challenged with the homologous antigen (Challacombe \& Tomasi, 1980). This experimental protocol has been widely used to analyse the mechanisms by which mucosal immune responses are controlled. Considerable progress has been made in understanding these mechanisms, and it is now clear that T-cell anergy, apoptosis and active regulation can all contribute under different conditions. However, these studies have not clarified two major issues. First, the sites and specific cellular and molecular interactions which generate the different mechanisms of tolerance have not been fully identified. Second, we do not fully understand how the mucosal immune system can generate tolerance against 'harmless' antigens and active responses against 'dangerous' antigens, and how, in normal individuals, these broad classes of antigens can be distinguished with a high extent of accuracy.

\section{Post-weaning diarrhoea in piglets}

The model system with which we have worked extensively is the introduction of novel food antigens to young piglets at weaning. The pig is a large single-stomached omnivore with a gastrointestinal physiology comparable with that of man and an immune system which is more accessible than the mouse. The litter size (ten to fourteen piglets) and the 
availability of lines inbred to a greater or lesser extent makes experimental manipulation easier than other larger domestic species. Intensive work by several groups over the last decade has advanced the situation with regard to immunological reagents and the pig is now a useful immunological model (Pescovitz, 1998; Haverson et al. 2001).

In true wild groups of pigs young piglets will continue to suckle until they are many months old, gradually increasing their intake of other food components as milk intake decreases. This situation, which presumably has provided evolutionary selection pressure under which the mammalian mucosal immune system has developed, allows gradual exposure to novel food antigens and gradual change in intestinal microflora, while under at least some protection from milk-derived, maternal immunoglobulin (Ig) A antibody. Under modern farming conditions, economics have dictated that piglets should be weaned from their sows much earlier than would occur in the wild. At present, weaning commonly occurs between 3 and 5 weeks old, at which point the piglets' voluntary intake of dry food is often limited. In some conditions, weaning can occur as early as $7-10 \mathrm{~d}$ old.

Conventional husbandry of piglets, therefore, provides a model of the ability of single-stomached mammals to cope with abrupt, early weaning, which is also of economic importance in its own right. At 3 weeks old, these piglets suddenly undergo massive challenge with antigens associated with food and with the establishment of a novel commensal intestinal bacterial flora. In addition, facultative pathogens, previously controlled but not eliminated by maternal $\operatorname{IgA}$ antibody, can expand and colonise. Thus, the mucosal immune system of the newly-weaned piglet must discriminate rapidly between an enormous range of 'harmless' and 'dangerous' antigens, determining which, if any, might be associated with pathogens and mounting appropriate responses. That these decisions are not always made appropriately is indicated by the observation that early weaning in piglets is always associated with a check in growth and frequently with diarrhoea of varying severity (Hampson, 1986). This outcome occurs as a consequence of atrophy of intestinal villi, hypertrophy of intestinal crypts and accelerated turnover of crypt cells resulting in shorter lifespan and altered state of differentiation (Miller et al. 1986). While toxic effects of overgrowth of intestinal bacteria may cause these changes, this type of pathology also occurs in a number of clean experimental models of active immune responses in the intestine, specifically in rodents sensitised to express active mucosal responses to ovalbumin or undergoing graft $v$. host responses (Mowat \& Ferguson, 1981, 1982). It is also a feature of a number of multifactorial conditions involving mucosal immune responses, such as infection with gastrointestinal nematodes or rejection crises in transplanted intestines in rodents and man (MacDonald \& Ferguson, 1976).

The occurrence of immune responses to fed proteins in weaned piglets has been well documented by several groups. Weaning at 3 weeks old onto soyabean-based diets results in rapid appearance of serum IgG antibody directed against glycinin and $\beta$-conglycinin, major storage components of the soyabean (Wilson et al. 1989; Dreau et al. 1994). The link between immune responses to soyabean and the intestinal pathology is suggested by a study in which a high proportion of the variation in weight gain after weaning could be accounted for by variation in indirect indices of mucosal immune responses (villus atrophy, crypt hyperplasia) and direct measures of systemic immune responses to soyabean (serum antibody, skin delayed-type hypersensitivity reactions; Li et al. 1991). Interestingly, serum antibody was, in fact, positively associated with weight gain, while delayed-type hypersensitivity reactions to intradermal soyabean were negatively associated; i.e. cellular or T-helper (Th) 1-type responses were most damaging, while antibody responses might be protective. This observation is consistent with studies on inflammatory bowel disease in rodents and man, where Th1 responses in the intestine are mostly associated with pathology.

In piglets weaned at 3 weeks old the level of the response to fed soyabean was comparable with that produced in response to injection of soyabean together with adjuvant (Bailey et al. 1994b). In contrast, when soyabean was introduced into the diet of older piglets, only limited antibody responses were observed (Wilson et al. 1989). Despite the occurrence of an initial strong active immune response to the fed protein, detected by systemic antibody, the response was still essentially mucosal. This factor was demonstrated first by dosing piglets with soyabean antigen at birth, which decreased the level of antibody produced at weaning in response to fed soyabean, but not injected soyabean (Bailey et al. 1994b). Second, the initial immune response was followed by tolerance rather than by priming; injection with soyabean at 9 weeks old, after the level of antibody had declined, triggered essentially no antibody compared with systemic primary or secondary responses in control groups (Bailey et al. 1993). Studies in piglets kept under conditions approaching the wild, in which weaning occurs gradually up to 12 weeks old, have shown that tolerance to soyabean proteins in these animals is not complete until after 9 weeks old (Miller et al. 1994).

The data from studies on the immune response to fed proteins in piglets weaned at 3 weeks old suggests that these animals do mount inappropriate immune responses to antigens in the weaning diet, but that these responses are subsequently controlled by classical 'oral tolerance' mechanisms. This observation has two important implications. First, that tolerance to mucosal antigen is likely to be mediated at the effector stage, rather than the inductive stage. Second, that neonatal infants and animals suddenly exposed to high levels of mucosal antigen are likely to respond inappropriately, generating allergy or failing to respond to pathogens.

\section{Sensitisation precedes tolerance in rodents}

The idea that mucosal tolerance is regulated at the effector stage is consistent with a number of observations in rodent models. In the early demonstrations of oral tolerance, it was shown that systemic tolerance, measured as reduced antibody responses to injected antigen, could be accompanied by secretory $\operatorname{IgA}$ responses to antigen within the intestine (Challacombe \& Tomasi, 1980). Since isotype switching by B-cells requires $\mathrm{T}$-cell cooperation, this response implies the presence of mucosal T-cells capable 
of engaging in effector mechanisms. This early study was followed by a series of experiments using an oral tolerance protocol in mice requiring five consecutive daily feeds with ovalbumin. Using this protocol, it was possible to demonstrate that the initial feeds resulted in immunological priming rather than tolerance, and that this process was associated with delayed-type hypersensitivity reactivity and mild intestinal pathology (Stokes et al. 1983). Again, the implication is that antigen-feeding results in the appearance of primed effector T-cells which are regulated at the effector stage, rather than progressing directly from naive to regulated cells. Very recently, studies in which presentation of food-derived antigens to T-cells in the intestine is altered have suggested that the phenomenon of orally-induced systemic tolerance may be completely unlinked to the control of immune-mediated damage in the intestinal mucosa. One hypothesis for maintenance of mucosal tolerance has been that presentation of peptide epitopes to T-cells in the context of major histocompatibility complex class II on non-professional presenting cells (enterocytes in man and rodents, endothelial cells in pigs) may result in tolerance due to failure to engage appropriate co-stimulatory molecules (Bland \& Warren, 1986; Mayer \& Shlien, 1987; Wilson et al. 1996). To test this hypothesis, mice were made transgenic for the co-stimulatory molecule CD80 under the control of the enterocyte-specific promoter for the fatty acid-binding protein (Iqbal et al. 1999). This transgene resulted in selective expression of CD80 on intestinal enterocytes and, consistent with the hypothesis, the transgenic mice could not be orally tolerised using standard protocols. If orally-induced systemic tolerance reflects the ability to control mucosal immune responses, then these mice should be expressing active immune responses against normal antigens in their diet. However, the intestines of these mice appear normal; i.e. expression of damaging mucosal immune responses in these mice is being controlled by mechanisms independent of systemic 'oral tolerance' and presumably in the intestinal mucosa.

\section{Organisation of mucosal effector sites}

The mucosal immune system in mammals consists of two main compartments. Organised lymphoid tissues are present both close to the mucosal surface, e.g. the Peyer's patches and palatine tonsils, and at sites of lymphatic drainage, such as the mesenteric lymph nodes. However, in addition, there is a large immunological component diffusely scattered through the mucosal epithelium and lamina propria. The size of this component is frequently underestimated; probably half the immunologically-relevant cells in the intestine are present in the villi and around the crypts, even in normal individuals. The organised lymphoid tissues, equipped with antigen-sampling cells (M-cells in the Peyer's patches or migrating dendritic cells in the draining lymph nodes), T-cell zones and B-cell follicles are clearly potential sites for induction of immune responses to novel mucosal antigens. In contrast, the intestinal mucosa has all the hallmarks of an effector site. The phenotype of T-cells normally resident in the mucosa is consistent with antigenexperienced T-cells. In man they express predominantly the low-molecular-weight CD45RO isoform of the leucocyte common antigen, although a proportion co-express CD45RB at variable level (Halstensen et al. 1990); in pigs, the majority similarly do not express the high-molecularweight CD45RC isoform (Bailey et al. 1998). In both species there appears to be low level expression of CD25 on the surface, again consistent with antigen recognition in the relatively recent past (Zeitz et al. 1988; Haverson et al. 1999). Freshly isolated human lamina propria T-cells secrete interferon- $\gamma$ and can be induced to secrete high levels of interleukin (IL)-2 by polyclonal activation (James et al. 1990; Hauer et al. 1998).

However, a number of observations suggest that lamina propria leucocytes are not simply effector cells, engaged in surveillance and in provision of recall responses to potential pathogens. In the intestines of mature pigs there is a high extent of spatial organisation inconsistent with simple infiltration as part of a process of 'controlled inflammation' (Vega-Lopez et al. 1993). T-cells are largely confined to the villi and do not appear around the crypts, while plasma cells are localised in the crypts rather than villi. Within the villi, $\mathrm{CD}^{+}$T-cells are present within and only immediately beneath the epithelium, while $\mathrm{CD} 4^{+} \mathrm{T}$-cells are present deep into the core of the villus (Wilson et al. 1996). Dendritic cells lie immediately underneath the epithelium, projecting dendrites into the epithelial layer and deep into the villus core (Haverson et al. 2000). Although the level of spatial organisation of the mucosa in man and rodents is not as marked as the pig, it does suggest that local immunological cells are carrying out specific controlled functions.

Activation of murine or pig lamina propria cells does not result in a high level production of IL-2: these cells preferentially produce IL-4 (Harriman et al. 1992; Bailey et al. 1994a). Production of IL-2 by human lamina propria cells requires activation through the $\mathrm{CD} 2$ surface molecule rather than through CD3; when CD3 is ligated, IL-4 is preferentially secreted, apparently due to alterations in intracellular signalling pathways (Targan et al. 1995; Boirivant et al. 1996a).

A crucial feature of mucosal T-cells suggesting that expression of effector function may not be their only function, and possibly not the main function, is their susceptibility to apoptosis. Studies in man have shown that isolated mucosal leucocytes are extremely sensitive to apoptosis in vitro. Intra-epithelial leucocytes expressing the thymusindependent $\gamma$ and $\delta$ T-cell receptors rapidly enter apoptosis pathways without activation (Viney \& MacDonald, 1990). Systemic T-cells from orally-tolerised mice also undergo apoptosis and are rescued by the presence of antigen (Garside et al. 1996). Susceptibility to apoptosis in the absence of antigen could be a simple mechanism for clearance of excess mucosal effector cells after resolution of antigen challenge, as has been proposed after acute systemic viral infections in man. However, while human and pig lamina propria leucocytes undergo limited apoptosis in resting cultures, apoptosis is markedly increased by activation (Boirivant et al. 1996b; FJ Plunkett, H-J Rothkötter, R Pabst, CR Stokes and M Bailey, unpublished results). Unlike true effector cells, apoptosis is apparently not due to cytokine deprivation, since exogenous IL-2 does not rescue lamina propria $\mathrm{CD}^{+}{ }^{+} \mathrm{T}$-cells from either man or pigs. 
Apoptosis within the villi, induced by antigen-recognition and activation, could be an extremely effective way of eliminating $\mathrm{T}$-cells generated by indiscriminate primary responses to harmless dietary antigens in organised lymphoid tissues.

In addition, studies on the production of regulatory cytokines suggest that immunoregulation may be an important function of T-cells in the intestinal mucosa. Experiments on oral tolerance in mice demonstrated that the organised lymphoid tissues of tolerised mice contained a population of T-cells, termed Th3 cells, capable of secreting high levels of transforming growth factor- $\beta$ (TGF $\beta$ ) in response to antigen (Santos et al. 1994). In parallel experiments TGF $\beta$ was shown to suppress antigen-induced proliferation by primed effector T-cells and to regulate colitis in one particular mouse model of inflammatory bowel disease (Powrie et al. 1996). These antigen-specific Th3 cells were, therefore, a potential mechanism for imposing mucosal tolerance, although only identified in organised tissues. A second cell type capable of regulating rodent inflammatory bowel disease was generated by cloning ovalbumin-specific T-cells in the presence of IL-10, and was characterised by its ability to secrete primarily IL-10 (Groux et al. 1997). This observation, that IL-10 is the primary driver for differentiation of IL-10-secreting regulatory T-cells, has been confirmed in a number of studies. The presence of regulatory T-cells at sites of antigenrecognition is potentially, therefore, a positive feedback loop, enforcing regulation in an antigen-non-specific manner. The ability of human and pig lamina propria leucocytes to secrete IL-10 at high levels again suggests that regulation may be a major function of the intestinal mucosa (Braunstein et al. 1997; FJ Plunkett, H-J Rothkötter, R Pabst, CR Stokes and M Bailey, unpublished results). Despite the demonstration of Th3 cells in organised lymphoid tissues, TGF $\beta$ production by lamina propria leucocytes has not been reported. However, TGF $\beta$ is produced by a wide range of stromal cells and TGF $\beta$ receptors are present on T-cells. Our studies in the pig suggest that TGF $\beta$ rescues lamina propria T-cells from apoptosis, and the role of TGF $\beta$ in colitic models may, in fact, be due primarily to an effect on T-cells rather than to T-cells secreting TGF $\beta$. This possibility has also been suggested by studies using dominantnegative transgenic mice in which TGF $\beta$ signalling is disrupted in T-cells but not in other cell types (Gorelik \& Flavell, 2000). These mice still develop the autoimmune pathology, suggesting that regulation requires T-cells responding to, rather than necessarily secreting, TGF $\beta$.

\section{Mechanisms for maintaining tolerance in the intestinal mucosa}

The division of the mucosal immune system into inductive and effector sites provides several distinct possibilities for controlling immune responses to harmless dietary antigens within the intestine. First, discrimination could be made within the organised lymphoid tissue at the inductive stage, resulting in functional deletion of antigen-specific T-cells by anergy or apoptosis and export of T-cells pre-committed to imposing tolerance. Second, the organised lymphoid tissues may simply export primed cells, which re-localise to the lamina propria and differentiate into effector or regulatory T-cells depending on the microenvironment. This process would have the effect of allowing combined signals from local antigen-presenting cells, from other T-cells, from matrix and from stromal cells to determine the outcome of antigen recognition. Integration of these signals by the T-cell could easily allow recognition of a stable microenvironment, resulting in differentiation into a regulatory T-cell, or recognition of 'damage', resulting in differentiation down classical pathways into effector T-cells.

In this model, in an animal continually exposed to specific dietary antigens, progressive waves of naive T-cells would undergo activation in organised lymphoid tissues, recirculation to the intestinal lamina propria and differentiation to a regulatory T-cell phenotype. Subsequent recognition of antigen would result in activation, secretion of regulatory cytokines and entry into apoptosis (Fig. 1). Local production of IL-4 would contribute to B-cell isotype switching to $\operatorname{IgA}$, while IL-10 would feed back on the next generation of incoming T-cells to promote differentiation into regulatory cells. Apoptosis is a necessary requirement of this system in order to prevent excessive accumulation of T-cells in the mucosa, particularly in a young animal with an active thymus which is continuously renewing the naive T-cell repertoire. In addition, it would provide a potential mechanism whereby tolerance could rapidly be converted to active immune responses as a result of changes in the microenvironment. This process may be more important than has been considered, since studies in rodents and man now suggest that tolerance, in addition to being expressed in response to food antigens, is also expressed to antigens of commensal intestinal bacteria in normal individuals (Duchmann et al. 1995a,b). Unfortunately, bacteria which exist as harmless commensals at one mucosal surface (the intestine) can be pathogenic in other mucosal sites. Examples are Escherichia coli mastitis in dairy cattle and in urinary tract infections in man. It seems likely that efficient immunological handling of commensal bacteria would include the ability to abandon tolerance under some circumstances.

The anti-proliferative effects of TGF $\beta$ in vitro and the demonstration that neutralisation in vivo can promote colitis in $\mathrm{CD}^{+}{ }^{+} \mathrm{T}$-cell-transplanted scid mice suggests that TGF $\beta$ is important in controlling mucosal inflammation. Our observation that TGF $\beta$ rescues lamina propria T-cells from apoptosis provides a mechanism for this control independent of the TGF $\beta$-producing Th3 cell observed in organised lymphoid tissues. The majority of TGF $\beta$ in normal mucosa is present as the inactive latent form, which requires processing to become active. In a stable intestinal mucosa CD4 ${ }^{+}$T-cell activation would progress into apoptosis in the presence of latent TGF $\beta$. Mucosal inflammation would result in conversion of latent to active TGF $\beta$ which would rescue $\mathrm{CD}^{+}{ }^{+} \mathrm{T}$-cells, allowing clonal expansion and increased secretion of IL-10 and IL-4 (Fig. 2). The combination of increased IL-4 and TGF $\beta$ would then promote IgA isotype switching, while increased IL-10 and TGF $\beta$ would contribute to re-enforcing T-cell tolerance. Importantly, once local inflammation was controlled and conversion to active TGF $\beta$ reduced, activated T-cells would once more enter apoptosis pathways. This process therefore provides a 


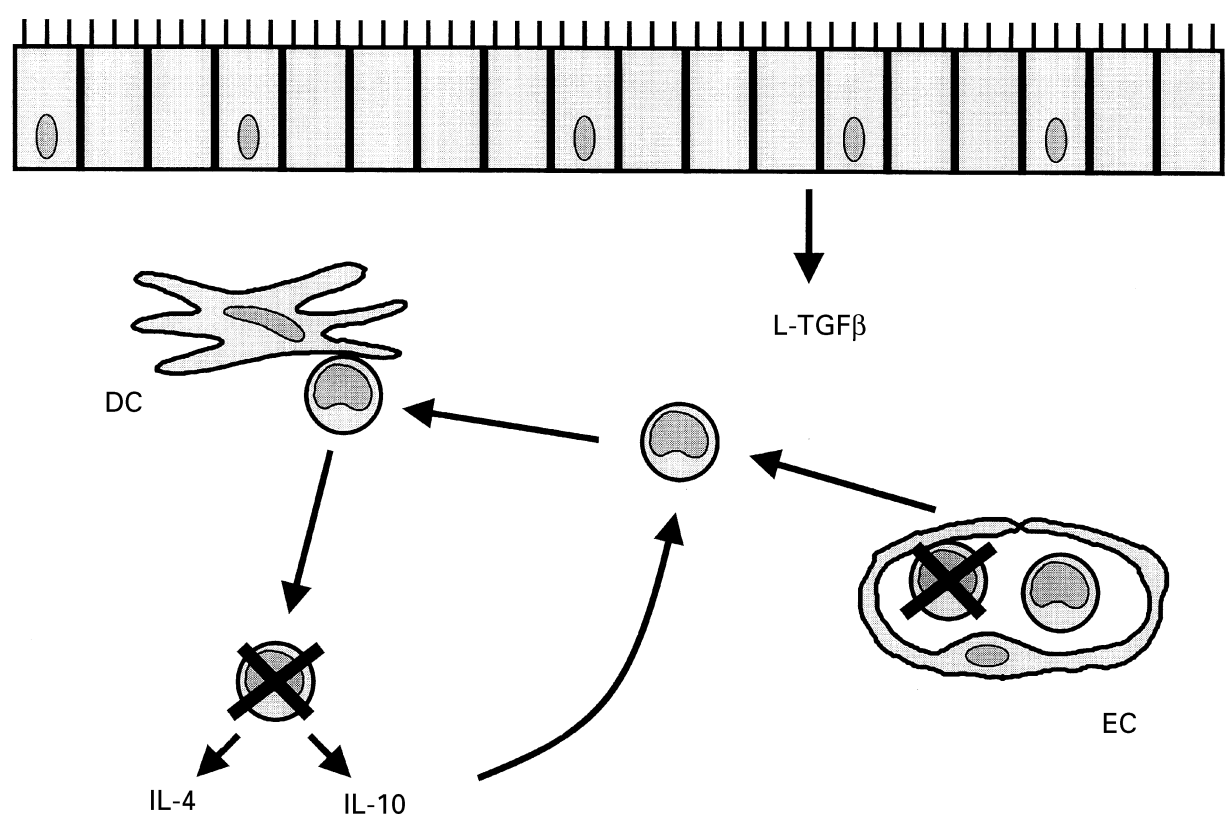

Fig. 1. Maintenance of homeostasis in the normal intestine. The majority of transforming growth factor- $\beta$ (TGF $\beta$ ) is present in the inactive latent form; when antigen-specific T-cells recognise antigen in the lamina propria, they activate in the presence of interleukin (IL) 10, becoming 'regulatory' T-cells which secrete further IL-10 and enter apoptosis after activation. EC, endothelial cell; DC, dendritic cell; L-TGF $\beta$, latent TGF $\beta$.

strongly-regulated system in which inflammation results in expression of local IgA responses while damping down inflammation and maintaining T-cell tolerance, as observed in rodent models of oral tolerance.

\section{Development of the mucosal immune system in the neonate}

The model proposed here for local regulation of T-cell responses in the intestine relies on the pre-existing presence of a microenvironment, to which existing regulatory T-cells contribute, which pushes differentiation of incoming antigen-specific T-cells towards a regulatory phenotype. In a normal adult animal the presence of regulatory T-cells specific for the homologous antigen or even for for other unrelated epitopes would provide local IL-10 which could enforce this pathway. However, this system is not present in neonatal animals, where exposure to mucosal antigens has been low. In the pig the mucosal immune system is almost completely absent at birth, although considerable development of the systemic immune tissue has taken place. Peyer's patches consist of primordial follicles surrounded by a small number of T-cells and are difficult to identify. Almost no immunological cells are present in the intestinal villi or between the crypts. Development of the spatiallyorganised architecture described for the mucosal immune system of the adult takes place over a period of several weeks in a series of defined stages, and is very largely dependent on microbial exposure (Bianchi et al. 1992; Vega-Lopez et al. 1995; Pabst \& Rothkotter, 1999). In conventional piglets development can be roughly divided into four distinct stages:
1. the newborn piglet; Peyer's patch follicles and T-cell areas are rudimentary. Almost no T-cells are present in the intestinal villi;

2. the first 2 weeks; follicles and T-cell areas of the Peyer's patches expand rapidly and the organisation present in mature animals is almost complete by $12 \mathrm{~d}$ old. Some conventional T-cells enter the intestinal villi, but the predominant cell expresses CD2 in the absence of CD4 or CD8. Currently, the nature of this cell is unclear. Expression of major histocompatibility complex class II antigens in the intestinal villi increases during this time;

3. $2-4$ weeks old; $\mathrm{CD}^{+}{ }^{+}$cells enter the intestinal mucosa and occupy the position in the core of the villi seen in the mature intestine;

4. 4 weeks onwards; $\mathrm{CD}^{+} \mathrm{T}$-cells enter the epithelium and lamina propria of the intestinal villi. The normal architecture present in mature animals is reached by about 6 weeks old, although absolute numbers continue to increase.

Importantly, very little of this development occurred when piglets were kept under germ-free conditions, suggesting that exposure to microbial antigen is an important driver for maturation of the immune system (Pabst et al. 1988; Rothkotter et al. 1991; Barman et al. 1997). In the case of T-cell development it is not known whether the effect of microbial flora is antigen-specific or non-specific. However, elegant studies on Ig gene rearrangement have demonstrated that the effect on mucosal B-cell development is almost certainly antigen-non-specific. Unlike man and rodents, but like the majority of other species characterised, the pig Ig heavy-chain gene contains only a single Jh 


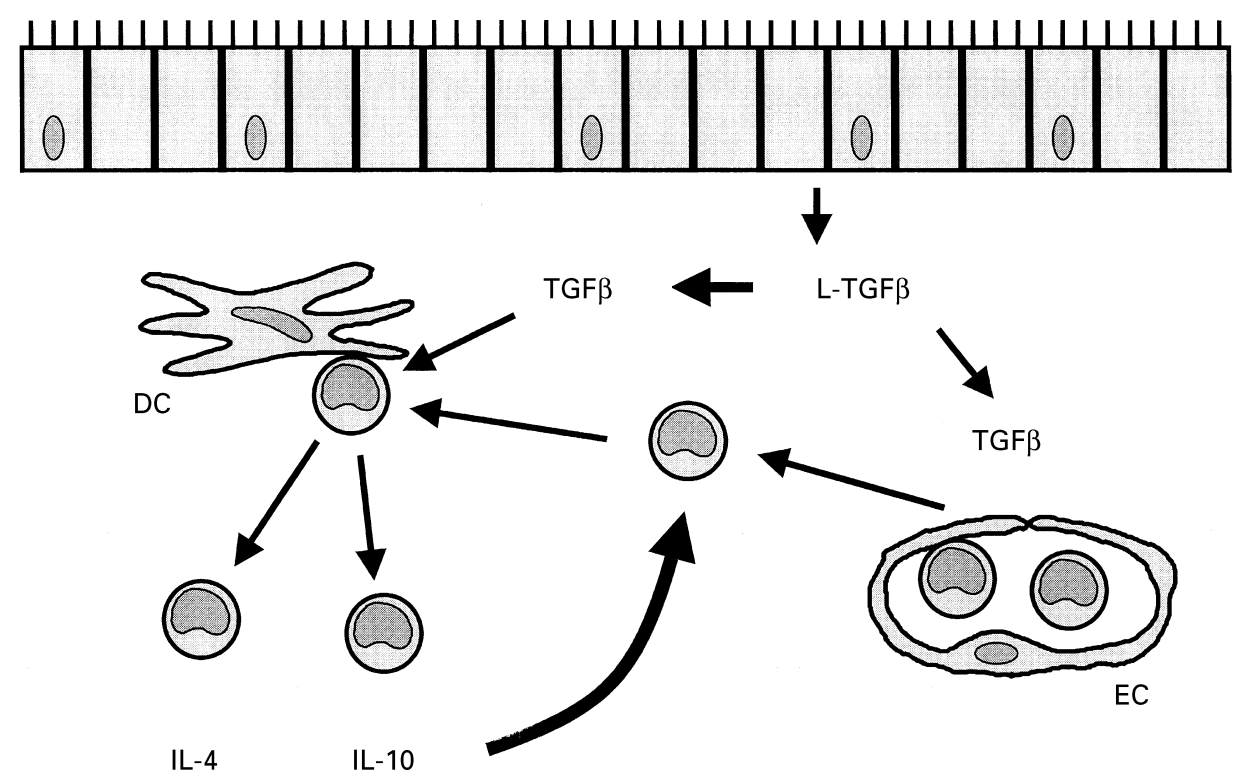

Fig. 2. Maintenance of homeostasis in the mildly-inflamed intestine. Conversion of latent to active transforming growth factor- $\beta$ (TGF $\beta$ ) results in clonal expansion of local T-cells. These populations can secrete higher levels of cytokines and the combination of interleukin (IL) 4, IL-10 and TGF $\beta$ predisposes to immunoglobulin A secretion and control of inflammatory processes. EC, endothelial cell; DC, dendritic cell; L-TGF $\beta$, latent TGF $\beta$.

segment. In the fetus and newborn piglet limited $\mathrm{Vh}$ and $\mathrm{Dh}$ segment usage $(80 \%$ of B-cells using four $\mathrm{V}$ segments and two D segments) resulted in a limited B-cell repertoire (Sun et al. 1998). In germ-free piglets this limited $\mathrm{Vh}$ and $\mathrm{Dh}$ segment usage persisted. However, in conventional piglets, or in germ-free piglets colonised with a defined intestinal flora, V segment usage increased, indicating increased repertoire (Butler et al. 2000). At the same time point mutations accumulated in IgM transcripts at the same rate as IgG transcripts, suggesting polyclonal activation unrelated to isotype switching.

In order to maintain digestive and absorptive intestinal function in the face of postnatal microbial colonisation, this development of the mucosal immune system must take place in a controlled regulated way. In other words, at all stages it must have the capacity to discriminate between 'harmless' and 'harmful' antigens and respond appropriately. Even at 3 weeks old, when very few $\mathrm{CD} 4^{+} \mathrm{T}$-cells were present in the mucosa, the bias of cytokine production was already towards IL-4 rather than IL-2 (Bailey et al. 1994a). It seems likely, therefore, that development occurs as a balance between effector and regulatory functions, and that intestinal integrity depends on maintaining this balance between certain safe limits (Fig. 3). A similar concept of balanced development of a mucosal immune system in young individuals has been proposed for the respiratory system, as a balance between Th1 and Th2 effector systems (Holt et al. 1997). However, it is difficult to see how the balance between a Th1 response and a Th2 response results in failure to develop damaging mucosal immune responses and, given the accumulating evidence for regulatory T-cells in the intestinal mucosa, a balance between effector and regulatory responses seems conceptually more useful. In the domestic pig, and perhaps the mouse, the phenotype of mucosal T-cells suggests that this balance is tilted towards regulatory function, whereas in man effector function seems to predominate, at least in the developing countries where such studies have been done, and this factor might be relevant to the increasing incidence of atopic disease.

Within this model, the disturbances associated with early weaning in piglets would result from transient imbalance between effector and regulatory function (Fig. 4). There is clear evidence for an effect of abrupt weaning on the immune system of neonatal pigs. Within $24 \mathrm{~h}$ of withdrawal of maternal milk, expression of major histocompatibility complex class II and CD3 mRNA was increased and by $4 \mathrm{~d}$ after weaning the numbers of $\mathrm{CD} 2^{+}$cells in the intestinal mucosa was increased (Dreau et al. 1995; Vega-Lopez et al. 1995; McCracken et al. 1999). During the first week, the

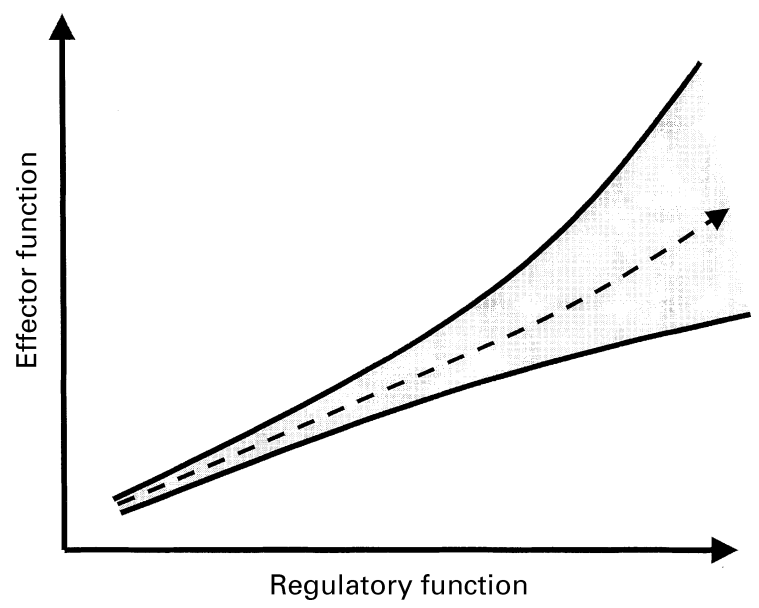

Fig. 3. Proposed model for the development of a mucosal immune system as a balance between regulatory and effector function. (回), The limits of a 'safe' balance, within which the developing piglet $(\rightarrow)$ must remain to maintain mucosal integrity. 
(a)

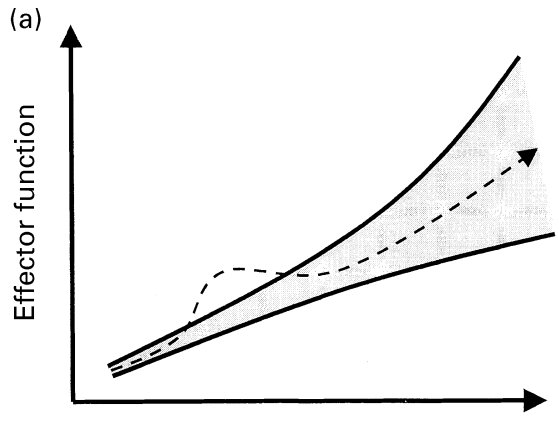

Regulatory function

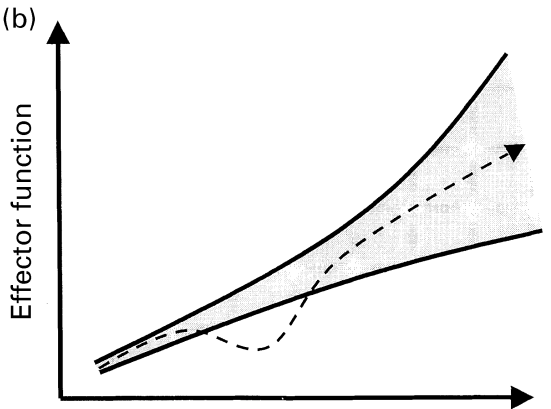

Regulatory function

Fig. 4. Transient disturbance of the balance as a result of weaning. (罜), The limits of a 'safe' balance, within which the developing piglet $(\rightarrow$ ) must remain to maintain mucosal integrity. (a), The developing piglet mounts inappropriate effector immune responses against 'harmless' antigens, resulting in transient allergic intestinal damage. (b), The piglet excessively regulates responses to potential pathogens, resulting in microbially-mediated damage.

ability of systemic T-cells to produce IL-2 in response to mitogens was decreased (Bailey et al. 1992; Wattrang et al. 1998). These effects may be a direct result of withdrawal of antibody or growth factors such as TGF $\beta$ in milk, of alterations in intestinal flora; or of physiological effects of environmental stress such as mixing in piglets or reduced maternal contact in man. The observed responses to soyabean antigens in young piglets and to cow's milk protein in human infants are consistent with the occurrence of excessive development or expression of effector function; excessive regulatory function is suggested by the overgrowth of largely non-pathogenic bacterial strains frequently associated with post-weaning diarrhoea.

In piglets the immunological and gastrointestinal disturbances associated with weaning are usually transient, and development of the mucosal immune system proceeds normally. However, it seems likely that under certain environmental or genetic conditions, transient disruption of the balance between mucosal effector and regulatory responses may become permanent. Depending on the imbalance, such animals or man would be permanently predisposed to development of allergies (excessive effector function) or to chronic infections (excessive regulatory function).

\section{Conclusions}

Maintenance of intestinal integrity and digestive and absorptive function is at least partly dependent on the ability of the mucosal immune system to discriminate between 'harmful' and 'harmless' antigens and mount appropriate responses (tolerance or active immunity). While one level of discrimination may take place within the organised lymphoid tissues during induction of an immune response, several lines of evidence suggest that regulation can occur after induction, implicating effector sites in discrimination. These effector sites are largely absent in the neonate, and develop with age and exposure to antigens. We propose that development occurs as a balance between effector and regulatory function, and that disturbances in this balance result in immediate disturbance of intestinal function, but may also, in some individuals, result in chronic allergic or infectious disease in later life.

\section{References}

Bailey M, Clarke CJ, Wilson AD \& Stokes CR (1992) Depressed potential for interleukin-2 production following early weaning of piglets. Veterinary Immunology and Immunopathology 34, 197-207.

Bailey M, Hall L, Bland PW \& Stokes CR (1994a) Production of cytokines by lymphocytes from spleen, mesenteric lymph node and intestinal lamina propria of pigs. Immunology 82, 577-583.

Bailey M, Miller BG, Telemo E, Stokes CR \& Bourne FJ (1993) Specific immunological unresponsiveness following active primary responses to proteins in the weaning diet of pigs. International Archives of Allergy and Immunology 101, 266-271.

Bailey M, Miller BG, Telemo E, Stokes CR \& Bourne FJ (1994b) Altered immune response to proteins fed after neonatal exposure of piglets to the antigen. International Archives of Allergy and Applied Immunology 103, 183-187.

Bailey M, Plunkett F, Clarke A, Sturgess D, Haverson K \& Stokes $\mathrm{C}$ (1998) Activation of $\mathrm{T}$ cells from the intestinal lamina propria of the pig. Scandinavian Journal of Immunology 48, 177-182.

Barman NN, Bianchi ATJ, Zwart RJ, Pabst R \& Rothkotter HJ (1997) Jejunal and ileal Peyers patches in pigs differ in their postnatal development. Anatomy and Embryology 195, 41-50.

Bianchi AT, Zwart RJ, Jeurissen SH \& Moonen-Leusen HW (1992) Development of the B- and T-cell compartments in porcine lymphoid organs from birth to adult life: an immunohistological approach. Veterinary Immunology and Immunopathology 33, 201-221.

Bland PW \& Warren LG (1986) Antigen presentation by epithelial cells of the rat small intestine. I. Kinetics, antigen specificity and blocking by anti-ia antisera. Immunology 58, 1-7.

Boirivant M, Fuss I, Fiocchi C, Klein JS, Strong SA \& Strober W (1996a) Hypoproliferative human lamina propria T-cells retain the capacity to secrete lymphokines when stimulated via CD2/CD28 pathways. Proceedings of the Association of American Physicians 108, 55-67.

Boirivant M, Pica R, Demaria R, Testi R, Pallone F \& Strober W (1996b) Stimulated human lamina propria T-cells manifest enhanced FAS-mediated apoptosis. Journal of Clinical Investigation 98, 2616-2622.

Braunstein J, Qiao L, Autschbach F, Schurmann G \& Meuer S (1997) T cells of the human intestinal lamina propria are high producers of interleukin-10. Gut 41, 215-220.

Butler JE, Sun J, Weber P, Navarro P \& Francis D (2000) Antibody repertoire development in fetal and neonatal piglets. 
III. Colonisation of the gastrointestinal tract selectively diversifies the preimmune repertoire in mucosal lymphoid tissues. Immunology 100, 119-130.

Challacombe SJ \& Tomasi B (1980) Systemic tolerance and secretory immunity after oral immunisation. Journal of Experimental Medicine 152, 1459-1472.

Dreau D, Lalles JP, Philouzerome V, Toullec R \& Salmon H (1994) Local and systemic immune responses to soybean protein ingestion in early-weaned pigs. Journal of Animal Science 72, 2090-2098.

Dreau D, Lalles JP, Toullec R \& Salmon H (1995) B-lymphocyte and T-lymphocyte are enhanced in the gut of piglets fed heattreated soybean proteins. Veterinary Immunology and Immunopathology 47, 69-79.

Duchmann R, Kaiser I, Hermann E, Mayet W, Ewe K \& zum Buschenfelde KHM (1995a) Tolerance exists towards resident intestinal flora but is broken in active inflammatory bowel disease (IBD). Clinical and Experimental Immunology 102, 448-455.

Duchmann R, Kaiser I, Hermann E, Mayet W, Ewe K \& zum Buschenfelde KHM (1995b) Tolerance exists towards resident intestinal flora but is broken in active inflammatory bowel disease (IBD). Clinical and Experimental Immunology 102, 448-455.

Garside P, Steel M, Worthey EA, Kewin PJ, Howie SEM, Harrison DJ, Bishop D \& Mowat AM (1996) Lymphocytes from orally tolerised mice display enhanced susceptibility to death by apoptosis when cultured in the absence of antigen in vitro. American Journal of Pathology 149, 1971-1979.

Gorelik L \& Flavell RA (2000) Abrogation of TGF $\beta$ signalling in $\mathrm{T}$ cells leads to spontaneous $\mathrm{T}$ cell differentiation and autoimmune disease. Immunity 12, 171-181.

Groux H, O'Garra A, Bigler M, Rouleau M, Antonenko S, deVries JE \& Roncarolo MG (1997) A CD4 ${ }^{+}$T-cell subset inhibits antigen-specific $\mathrm{T}$ cell responses and prevents colitis. Nature 389, 737-742.

Halstensen TS, Scott H \& Brandtzaeg P (1990) Human CD8 ${ }^{+}$ intraepithelial $\mathrm{T}$ lymphocytes are mainly $\mathrm{CD} 45 \mathrm{RA}^{-} \mathrm{RB}^{+}$and show increased co-expression of CD45RO in celiac disease. European Journal of Immunology 20, 1825-1830.

Hampson DJ (1986) Alterations in piglet small intestinal structure at weaning. Research in Veterinary Science 40, 32-40.

Harriman GR, Hornqvist E \& Lycke NY (1992) Antigenspecific and polyclonal $\mathrm{CD}^{+}$lamina propria T-cell lines phenotypic and functional characterisation. Immunology $\mathbf{7 5}$, 66-73.

Hauer AC, Bajaj-Elliott M, Williams CB, Walker-Smith JA \& MacDonald TT (1998) An analysis of interferon gamma, IL-4, IL-5 and IL-10 production by elispot and quantitative reverse transcriptase pcr in human Peyers patches. Cytokine 10, $627-634$.

Haverson K, Bailey M \& Stokes CR (1999) T-cell populations in the pig intestinal lamina propria: memory cells with unusual phenotypic characteristics. Immunology 96, 66-73.

Haverson K, Saalmuller A, Alvarez B, Alonso F, Bailey M, Bianchi ATJ, Boersma WJA, Chen Z, Davis WC, Dominguez J, Engelhardt H, Ezquerra A et al. (2001) Overview of the third international workshop on swine leucocyte differentiation antigens. Veterinary Immunology and Immunopathology 80, 5-23.

Haverson K, Singha S, Stokes CR \& Bailey M (2000) Professional and non-professional antigen-presenting cells in the porcine small intestine. Immunology 101, 1-13.

Holt PG, Yabuhara A, Prescott S, Venaille T, Macaubas C, Holt BJ, Bjorksten B \& Sly PD (1997) Allergen recognition in the origin of asthma. CIBA Foundation Symposium 206, 35-55.
Iqbal N, Oliver JR, McCabe RP, Elson CO \& Weaver CT (1999) B7-1 expression on intestinal epithelium prevents oral tolerance induction. FASEB Journal 13, A606.

James SP, Kwan WC \& Sneller MC (1990) T cells in the inductive and effector compartments of the intestinal mucosal immune system of nonhuman primates differ in lymphokine mRNA expression, lymphokine utilisation and regulatory function. Journal of Immunology 144, 1251-1256.

Li DF, Nelssen JL, Reddy PG, Blecha F, Klemm R \& Goodband RD (1991) Interrelationship between hypersensitivity to soybean proteins and growth performance in early-weaned pigs. Journal of Animal Science 69, 4062-4069.

McCracken BA, Spurlock ME, Roos MA, Zuckermann FA \& Gaskins HR (1999) Weaning anorexia may contribute to local inflammation in the piglet small intestine. Journal of Nutrition 129, 613-619.

MacDonald TT \& Ferguson A (1976) Hypersensitivity reactions in the small intestine. 2. Effects of allograft rejection on mucosal architecture and lymphoid cell infiltrate. Gut 17, 81-89.

Mayer L \& Shlien R (1987) Evidence for function of Ia molecules on gut epithelial cells in man. Journal of Experimental Medicine 166, 1471-1483.

Miller BG, James PS, Smith MW \& Bourne FJ (1986) Effect of weaning on the capacity of the pig intestinal villi to digest and absorb nutrients. Journal of Agricultural Science, Cambridge 107, 579-589.

Miller GG, Whittemore CT, Stokes CR \& Telemo E (1994) The effect of delayed weaning on the development of oral tolerance to soya-bean protein in pigs. British Journal of Nutrition 71, 615-625.

Mowat AM \& Ferguson A (1981) Hypersensitivity in the small intestinal mucosa. V. induction of cell-mediated immunity to a dietary antigen. Clinical and Experimental Immunology 43, 574-582.

Mowat AM \& Ferguson A (1982) Intraepithelial count and crypt hyperplasia measure the mucosal component of the graft-versushost reaction in mouse small intestine. Gastroenterology 83, 417-423.

Pabst R, Geist M, Rothkotter HJ \& Fritz FJ (1988) Postnatal development and lymphocyte production of jejunal and ileal Peyers patches in normal and gnotobiotic pigs. Immunology $\mathbf{6 4}$, 539-544.

Pabst R \& Rothkotter H-J (1999) Postnatal development of lymphocyte subsets in different compartments of the small intestine of pigs. Veterinary Immunology and Immunopathology 72, 167-173.

Pescovitz MD (1998) Immunology of the pig. In Handbook of Vertebrate Immunology, pp. 373-420 [P-P Pastoret, P Griebel, H Bazin and A Govaerts, editors] London: Academic Press.

Powrie F, Carlino J, Leach MW, Mauze S \& Coffman RL (1996) A critical role for transforming growth factor beta but not interleukin-4 in the suppression of Thelper type 1-mediated colitis by $\mathrm{CD} 45 \mathrm{RB}(\mathrm{low}) \mathrm{CD} 4+\mathrm{T}$ cells. Journal of Experimental Medicine 183, 2669-2674.

Rothkotter HJ, Ulbrich H \& Pabst R (1991) The postnatal development of gut lamina propria lymphocytes: number, proliferation and $\mathrm{T}$ and $\mathrm{B}$ cell subsets in conventional and germ-free pigs. Pediatric Research 29, 237-242.

Santos LMB, Al-Sabbagh A, Londono A \& Weiner HL (1994) Oral tolerance to myelin basic protein induces regulatory TGF $\beta$ secreting T-cells in Peyers patches of SJL mice. Cellular Iтmиnology 157, 439-447.

Stokes CR, Newby TJ \& Bourne FJ (1983) The influence of oral immunisation on local and systemic immune responses to heterologous antigens. Clinical and Experimental Immunology 52, 399-406. 
Sun J, Hayward C, Shinde R, Christensen R, Ford SP \& Butler JE (1998) Antibody repertoire development in fetal and neonatal piglets. I. four $\mathrm{V}_{H}$ genes account for $80 \%$ of $\mathrm{V}_{H}$ usage during 84 days of fetal life. Journal of Immunology 161, 5070-5078.

Targan SR, Deem RL, Liu M, Wang S \& Nel A (1995) Definition of a lamina propria T-cell responsive state - enhanced cytokine responsiveness of T-cells stimulated through the CD2 pathway. Journal of Immunology 154, 664-675.

Vega-Lopez MA, Bailey M, Telemo E \& Stokes CR (1995) Effect of early weaning on the development of immune cells in the pig intestine. Veterinary Immunology and Immunopathology 44, 319-327.

Vega-Lopez MA, Telemo E, Bailey M, Stevens K \& Stokes CR (1993) Immune cell distribution in the small intestine of the pig: immunohistological evidence for an organized compartmentalization in the lamina propria. Veterinary Immunology and Immunopathology 37, 49-60.
Viney JL \& MacDonald TT (1990) Selective death of T-cell receptor $\gamma / \delta$ intaepithelial lymphocytes by apoptosis. European Journal of Immunology 20, 2809-2812.

Wattrang E, Wallgren P, Lindberg A \& Fossum C (1998) Signs of infections and reduced immune functions at weaning of conventionally reared and specific pathogen free pigs. Journal of Veterinary Medicine 45B, 7-17.

Wilson AD, Haverson K, Bland PW, Stokes CR \& Bailey M (1996) Expression of class II MHC antigens on normal pig intestinal endothelium. Immunology 88, 98-103.

Wilson AD, Stokes CR \& Bourne FJ (1989) Effect of age on absorbtion and immune responses to weaning or introduction of novel dietary antigens in pigs. Research in Veterinary Science 46, 180-186.

Zeitz M, Green WC, Peffer NJ \& James SP (1988) Lymphocytes isolated from the intestinal lamina propria of normal non-human primates have increased expression of genes associated with $\mathrm{T}$ cell activation. Gastroenterology 94, 647-655. 